\title{
Assessment of patient satisfaction with the preoperative anesthetic evaluation
}

\author{
This article was published in the following Dove Press journal: \\ Patient Related Outcome Measures \\ 16 September 2014 \\ Number of times this article has been viewed
}

\section{Endale Gebreegziabher Gebremedhn Vidhya Nagaratnam}

Department of Anesthesia, School of Medicine, Gondar College of Medicine and Health Sciences, University of Gondar, Gondar, Ethiopia
Correspondence: Endale Gebreegziabher Gebremedhn

Department of Anesthesia,

School of Medicine, Gondar College

of Medicine and Health Sciences,

University of Gondar, PO Box 196,

Gondar, Ethiopia

$\mathrm{Tel}+251910880117$

Email endalege@yahoo.com
Background: The evaluation of patient satisfaction is a core aspect of the continuous quality improvement in anesthesia service that can be affected by the preoperative anesthetist visit. This visit enables the anesthetist to know about the patient's general health status and the nature of surgery, to choose the type of anesthesia, and to discuss perioperative complications and their management with the patient. Patients have sometimes complained about the information given during the preoperative anesthetic evaluation in the University of Gondar teaching and referral hospital. The aim of this study was to determine the level of patient satisfaction with the preoperative anesthetist visit.

Methods: A cross-sectional study was conducted from February 15 to April 15, 2013. All consecutive elective patients who were operated upon under anesthesia during the study period were interviewed 24 hours after operation. A pretested questionnaire and checklists, which were developed based on the hospital's anesthetic evaluation sheet, were used for data collection.

Results: A total of 116 elective patients were operated upon under anesthesia during the study period. Of these, 102 patients were included in our study, with a response rate of $87.9 \%$. Anesthetists introduced themselves to $\sim 24 \%$ patients; provided information about anesthesia to $\sim 32 \%$, postoperative complications to $\sim 21 \%$, postoperative analgesia to $\sim 18$, and postoperative nausea and vomiting to $\sim 21 \%$; and spent adequate time with $\sim 74 \%$. Patients' questions were answered by the anesthetist in $\sim 65 \%$ of cases, and $\sim 65 \%$ of patients had reduced anxiety after the anesthetist visit. The patients' overall satisfaction with the preoperative anesthetist visit was $\sim 65 \%$.

Conclusion and recommendation: Patient satisfaction with the preoperative anesthetic evaluation was low compared with the Royal College of Anaesthetists standards. Preoperative anesthetic evaluation should be emphasized.

Keywords: anesthetist visit, elective surgery

\section{Introduction}

The evaluation of patient satisfaction is a core aspect of the continuous quality improvement in anesthesia services. This can be significantly affected by the preoperative anesthetist visit. ${ }^{1-3}$

Preoperative anesthetist visits and preparation are important parts of anesthetic provision. It is useful to know about the patient's general status and nature of surgery and to choose the type of anesthesia. This creates a chance for the patients to get to know the anesthetist, to learn about anesthesia options, and to discuss postoperative pain, nausea, and vomiting management options and other possible complications. In addition, preoperative assessment decreases patient anxiety, minimizes 
the cancellation of surgery by surgeons and anesthetists, improves the patient's experience of their hospital stay, and may reduce complication rates and mortality. ${ }^{4-7}$

Preoperative assessment is also important in terms of obtaining consent. ${ }^{8-10}$ Although anesthesia services differ from country to country across the world, they should be as comprehensive as possible. The anesthesia service in the University of Gondar teaching and referral hospital starts with the preoperative evaluation of patients during the night before the day of surgery, in the respective wards, with the aims of assessing the patient's medical condition; evaluating the patient's overall health status; determining risk factors related to anesthesia; educating the patient; discussing the techniques of anesthesia and available options for postoperative management; and obtaining consent. Patients who are scheduled for day case surgery are evaluated a few days before the day of surgery and are briefly reevaluated on the day of surgery. However, no study has been conducted in our hospital that could show the level of patient satisfaction with the preoperative anesthetic evaluation. The aim of the present study was to determine the level of patient satisfaction with the preoperative anesthetic evaluation over a wide range of surgical specialties and among patients operated upon under both general and regional anesthesia during the study period.

\section{Methods}

\section{Study design and period}

This study was designed as a cross-sectional study to determine patient satisfaction with the preoperative anesthetic evaluation. Following ethical approval by the institutional ethical approval committee, the study was conducted at the University of Gondar teaching and referral hospital from February 15 to April 15, 2013.

\section{Study subjects}

All consecutive admitted elective patients who were operated upon under anesthesia during the data collection period were included. There were no day case surgeries during the study period. Those patients who were discharged earlier than 24 hours after operation were excluded.

\section{Data collection method}

We pretested the questionnaire by performing a pilot study on 15 patients (eight adults and seven children) at another hospital (Ibex General hospital, Gondar), using questions and checklists developed based on our hospital's anesthetic evaluation sheet, to check whether the data collection tool was suitable for the patients and data collectors. Corrections were made after the pretest, before the start of data collection. However, we did not involve a panel of experts to check the validity of the questionnaire. The patients were interviewed 24 hours after operation using an anonymous questionnaire. The parents or guardians were interviewed in addition to the patients for those $<15$ years old so appropriate information could be obtained, except in the cases of small children, infants, and neonates (only the parents were interviewed). The patients were interviewed by two trained Bachelor of Science-holding nurses. We trained the data collectors twice during the study period (before the start of data collection and in the middle of the study period) on how to make each question or piece of information clear to the respondents during the interview. We did not use a separate tool to quantifiably measure how well each patient understood the information. The results were compared with the Royal College of Anaesthetists' preoperative anesthetic evaluation standards (Table 1).

\section{Operational definitions}

\section{Major operation}

A major operation was defined as any invasive operative procedure in which a more extensive resection is performed, eg, a body cavity is entered, organs are removed, or normal anatomy is altered - in general, if a mesenchymal barrier was opened (pleural cavity, peritoneum, meninges).

Table I Standards for the preoperative anesthetic evaluation of patients

\begin{tabular}{llll}
\hline $\begin{array}{l}\text { Standard } \\
\text { number }\end{array}$ & Standard & Source & Target \\
\hline 1 & $\begin{array}{l}\text { Seen by anesthetist } \\
\text { before surgery } \\
\text { Self-introduction done } \\
\text { by anesthetist }\end{array}$ & RCOA & $100 \%$ \\
2 & $\begin{array}{l}\text { Patient history taken } \\
\text { by anesthetist }\end{array}$ & RCOA & $100 \%$ \\
3 & $\begin{array}{l}\text { Physical examination done } \\
\text { by anesthetist }\end{array}$ & RCOA & $100 \%$ \\
4 & $\begin{array}{l}\text { Fasting instructions given } \\
\text { Awareness of type of anesthesia } \\
\text { before surgery }\end{array}$ & RCOA & $100 \%$ \\
6 & $\begin{array}{l}\text { Awareness about the possible } \\
\text { anesthesia complications }\end{array}$ & RCOA & $100 \%$ \\
7 & $\begin{array}{l}\text { Awareness of modes } \\
\text { of postoperative analgesia } \\
\text { Awareness about the options } \\
\text { for PONV management }\end{array}$ & RCOA & $100 \%$ \\
\hline 9 & RCOA & $100 \%$ \\
\hline
\end{tabular}

Abbreviations: PONV, postoperative nausea and vomiting; RCOA, The Royal College of Anaesthetists. 


\section{Minor operation}

A minor operation was defined as any invasive operative procedure in which only skin or mucus membranes and connective tissue are resected, eg, vascular cutdown for catheter placement or implanting pumps in subcutaneous tissue.

\section{Data analysis}

SPSS for Windows software (v 20.0) was used for data entry and analysis. Tables were used for presentation of descriptive statistics.

\section{Results}

A total of 116 elective patients were operated upon under anesthesia during the study period. Of these, 14 patients were discharged earlier than 24 hours after operation. A total of 102 elective patients were included in our study, with a response rate of $87.9 \%$. The maximum and minimum ages were 80 years and 9 months, respectively. The mean age was 32.75 years.

A total of 22 anesthetists were involved in anesthesia services during the study period (Table 2).

Anesthetists introduced themselves to 24 (23.5\%) patients, and $33(32.4 \%)$ and 21 (20.6\%) patients received information about the type of anesthesia and possible postoperative complications, respectively (Table 3).

Anesthetists spent adequate time with 75 (73.5\%) patients and gave information about postoperative nausea and vomiting (PONV) to 21 (20.6\%) patients during the preoperative evaluation (Table 4).

Table 2 Sociodemographic characteristics of the participants

\begin{tabular}{lll}
\hline Factor & Frequency & Percentage \\
\hline Sex & 51 & \\
$\quad$ Male & 51 & 50 \\
$\quad$ Female & & 50 \\
Age & 27 & \\
$\quad \leq 18$ years & 24 & 26.5 \\
19-29 years & 30 & 23.5 \\
$30-49$ years & 12 & 29.4 \\
$50-65$ years & 9 & 11.8 \\
$>65$ years & & 8.8 \\
Type of operation & 99 & \\
$\quad$ Major & 3 & 97.1 \\
Minor & & 2.9 \\
Number of years of experience & & \\
of anesthetists & 4 & 18.2 \\
$\quad<1$ year & 5 & 22.7 \\
I-2 years & 6 & 27.3 \\
3-5 years & 7 & 31.8 \\
$>5$ years &
\end{tabular}

Table 3 Preoperative visits of patients with anesthetists, March 15 to April I5, $2013(\mathrm{~N}=102)$

\begin{tabular}{|c|c|c|}
\hline Factor & Frequency & Percentage \\
\hline \multicolumn{3}{|c|}{ Patient seen by anesthetist } \\
\hline Yes & 102 & 100.0 \\
\hline No & 0 & 00.0 \\
\hline \multicolumn{3}{|c|}{ Anesthetist introduced } \\
\hline \multicolumn{3}{|c|}{ him/herself } \\
\hline Yes & 24 & 23.5 \\
\hline No & 78 & 76.5 \\
\hline \multicolumn{3}{|c|}{ History was taken } \\
\hline Yes & 102 & 100.0 \\
\hline No & 0 & 00.0 \\
\hline \multicolumn{3}{|c|}{ Physical examination was done } \\
\hline Yes & 99 & 97.1 \\
\hline No & 3 & 2.9 \\
\hline \multicolumn{3}{|c|}{ Fasting instruction was given } \\
\hline Yes & 93 & 91.2 \\
\hline No & 9 & 8.8 \\
\hline \multicolumn{3}{|c|}{ Information about anesthesia } \\
\hline \multicolumn{3}{|c|}{ type was given } \\
\hline Yes & 33 & 32.4 \\
\hline No & 69 & 67.6 \\
\hline \multicolumn{3}{|c|}{ Information about postoperative } \\
\hline \multicolumn{3}{|c|}{ complications was given } \\
\hline Yes & 21 & 20.6 \\
\hline No & 81 & 79.4 \\
\hline \multirow{2}{*}{\multicolumn{3}{|c|}{$\begin{array}{l}\text { Information about postoperative } \\
\text { analgesia was given }\end{array}$}} \\
\hline & & \\
\hline Yes & 18 & 17.6 \\
\hline No & 84 & 82.4 \\
\hline \multicolumn{3}{|c|}{ Information about PONV } \\
\hline \multicolumn{3}{|c|}{ management was given } \\
\hline Yes & 21 & 20.6 \\
\hline No & 81 & 79.4 \\
\hline
\end{tabular}

Abbreviation: PONV, postoperative nausea and vomiting.

\section{Overall patient satisfaction with the preoperative anesthetist visit and other factors}

We cross tabulated the overall satisfaction of patients with each factor to see how each factor affected the overall satisfaction of patients. Patient satisfaction about the preoperative anesthetist visit was markedly affected by a minor operation (major $63.6 \%$ versus minor 100\%). Even though all the patients were visited by anesthetists during the preoperative period, the patient satisfaction was lower than expected.

Self-introduction of anesthetists during the preoperative visits with patients was not directly related to patient satisfaction with the preoperative anesthetist visit.

History-taking during the preoperative anesthetist visit increased patient satisfaction even if the finding in this audit was lower than expected. However, preoperative 
Table 4 Preoperative visits of patients with anesthetists, March I5 to April 15, $2013(\mathrm{~N}=102)$

\begin{tabular}{lll}
\hline Factor & Frequency & Percentage \\
\hline $\begin{array}{l}\text { Anesthetist spent adequate } \\
\text { time with patient }\end{array}$ & \\
$\quad$ Yes & 75 & 73.5 \\
$\quad$ No & 27 & 26.5 \\
Patient's questions & & \\
were answered adequately & 66 & 64.7 \\
$\quad$ Yes & 36 & 35.3 \\
No & & \\
$\begin{array}{l}\text { Patient felt less anxious } \\
\text { after anesthetist visit }\end{array}$ & & \\
$\quad$ Yes & 66 & 64.7 \\
No & 36 & 35.3 \\
Patient was satisfied with the & & \\
preoperative anesthetist visit & & 64.7 \\
Yes & 66 & 35.3 \\
No & 36 & \\
\hline
\end{tabular}

physical examination was not directly related to patient satisfaction.

Patient satisfaction in respect of preoperative fasting instructions was substandard, despite the fact that the majority of patients were given fasting instructions. On the other hand, patient satisfaction in patients who received preoperative information about the type of anesthesia was high compared to that of those who did not receive such information ( $72.7 \%$ versus $60.8 \%)$.

Patient satisfaction was higher in patients who received preoperative information about postoperative complications than in those who did not ( $85.7 \%$ versus $59.3 \%$ ). On the other hand, patient satisfaction in those patients who had preoperative awareness about postoperative analgesia options during the preoperative visit was high compared with those patients who did not have such awareness (100\% versus $57.1 \%$ ).

Patient satisfaction was higher in patients who received preoperative information about PONV and its management than in those who did not (71.4\% versus $62.9 \%)$, but the adequacy of time the anesthetists spent with the patients during the preoperative visits was not directly related to patient satisfaction.

Patient satisfaction was higher in those who had their questions answered adequately by anesthetists than in those who did not (68.2\% versus 58.3\%). Patient satisfaction was higher in patients who had decreased anxiety after the preoperative anesthetist visit than in those who did not ( $73 \%$ versus $50 \%$ ).

The overall satisfaction of patients with the preoperative anesthetist visit was markedly affected by the number of years of experience of the anesthetists (Figure 1).

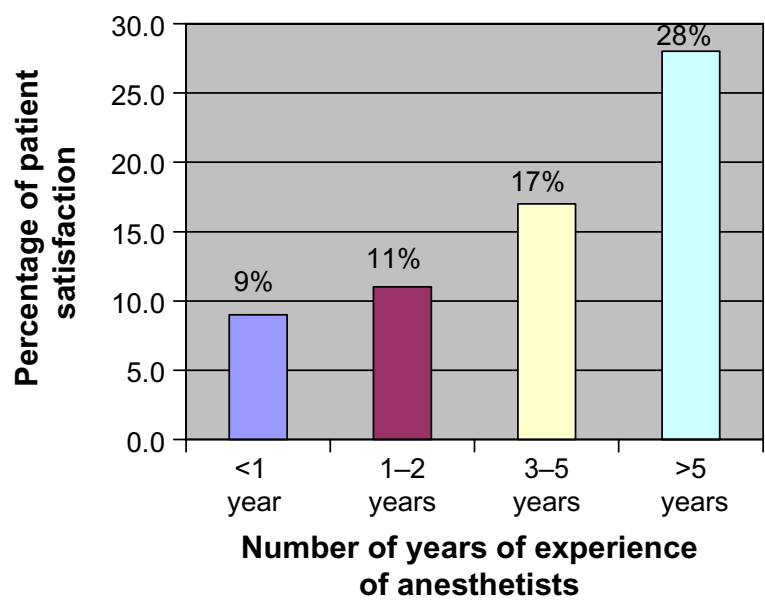

Figure I The effect of the number of years of experience of anesthetists on patients' satisfaction with preoperative anesthetist visits.

\section{Discussion}

The preoperative evaluation of a surgical patient by an anesthetist is an important interaction between the patient and the anesthetist. This evaluation allows the anesthetist to properly assess the patient's medical condition; evaluate the patient's overall health status; determine risk factors related to anesthesia; educate the patient; discuss the techniques of anesthesia and available options for postoperative management; and obtain consent.

During the preoperative evaluation, the patient can get a clear understanding of the planned anesthesia and the complications that might arise in the perioperative period. Problems which will be identified during this evaluation process may also be solved before surgery, or, sometimes, surgery may be delayed. All these processes can improve anesthesia safety, which contributes greatly to a better outcome for surgical patients. Patient satisfaction is also considered an important indicator of the quality of health care provision.

This clinical audit revealed that patient satisfaction with the preoperative anesthetist visit was low. This might be due to the inability to receive adequate information about anesthesia options, potential side effects, and complications of anesthesia, as well as about management of complications that might arise during the perioperative period. Lack of information about the responsible anesthetist and their role in the management of the patient during and after the operation may also be a factor.

Even though all patients were visited by anesthetists, few anxiety reduction techniques were used during the preoperative evaluation of the patients, which can be evidenced by the information provided in the areas of anesthetists' self- 
introductions; the adequacy of time spent by the anesthetists with the patients; the adequacy of the anesthetists' responses to patients' questions; and reduction of anxiety felt by patients after the anesthetist visit (Tables 3 and 4). Preoperative anxiety that might be caused by lack of adequate information about anesthesia and surgery is one of the most common causes of patient dissatisfaction in patients undergoing operation, which is reflected in this study. This finding was not, however, in agreement with a study conducted in Greece. ${ }^{3}$ This discrepancy might be due to a well-organized preoperative patient evaluation and postoperative patient management strategy in Greece, which did not exist in our case. On the other hand, our finding was in line with a study conducted in Sri Lanka. ${ }^{4}$

In this study, the fact that only a small number of patients (33 [32.4\%]) were given information about the type of anesthesia may have led to high rates of anxiety, which can lead to dissatisfaction. This finding was in line with a study conducted in Sri Lanka. ${ }^{7}$

The amount of information given about the possible postoperative complications and their management options, postoperative analgesia, and PONV was low (Table 3). It is clear that fear of anesthesia, surgery, postoperative pain, postoperative nausea and vomiting are some of the most common factors causing significant patient dissatisfaction in patients undergoing elective operation. The amount of information given for the patients was inadequate compared with the Royal College of Anaesthetists' preoperative anesthetic evaluation standards.

\section{Conclusion}

Overall patient satisfaction with the preoperative anesthetist visit was low (64.7\%) in our hospital. The preoperative patient visit, history-taking, and physical examination were almost in line with the Royal College of Anaesthetists' preoperative anesthetic evaluation standards. There was also relatively good practice regarding preoperative fasting instructions and the adequacy of time spent by the anesthetists with the patients. On the other hand, there were issues in the areas of anesthetists' self-introductions; information provision about type of anesthesia, postoperative complications, options for postoperative analgesia, and PONV management; anesthetists' responses to patients' questions; and techniques for reassuring patients.

\section{Recommendations}

Information about the importance of proper preoperative patient evaluation needs to be provided to the University of Gondar hospital anesthetists.

Training should be given to anesthetists in the areas of self-introduction; provision of information about the type of anesthesia, postoperative complications, options for postoperative analgesia, and PONV management; responses to patients' questions; and techniques for reassuring patients.

\section{Author contributions}

Endale Gebreegziabher Gebremedhn conceived the study and developed the proposal, collected the data, analyzed the data, and drafted the paper. Vidhya Nagaratnam revised the proposal and was involved in data collection, data analysis, writing of the final paper, and manuscript preparation along with Endale Gebreegziabher Gebremedhn. Both authors approved the final manuscript and agreed to publication in Patient Related Outcome Measures.

\section{Disclosure}

The authors report no conflicts of interest in this work.

\section{References}

1. Saal D, Heidegger T, Nuebling M, Germann R. Does a postoperative visit increase patient satisfaction with anaesthesia care? Br J Anaesth. 2011;107(5):703-709.

2. Le May S, Hardy JF, Taillefer MC, Dupuis G. Patient satisfaction with anesthesia services. Can J Anaesth. 2001;48(2):153-161.

3. Kouki P, Matsota P, Christodoulaki K, et al. Greek surgical patients' satisfaction related to perioperative anesthetic services in an academic institute. Patient Prefer Adherence. 2012;6:569-578.

4. Cooray TC. Audit to evaluate the patients view, regarding the preoperative visit of the patients by the anaesthetist. Sri Lankan Journal of Anaesthesiology. 2011;19(1):39-42.

5. Pre-Operative Assessment and Preparation. The Role of the Anaesthetist AAGBI; 2010. Available from: http://www.aagbi.org/sites/default/files/ preoperativeass01.pdf. Accessed September 4, 2014.

6. Consent for Anaesthesia. AAGBI; 2006. Available from: http://www aagbi.org/sites/default/files/consent06.pdf. Accessed September 4, 2014.

7. Vyhunthan G, Aeshana de Silva NG. Audit to evaluate preoperative visit to patient by anaesthetist. Sri Lankan Journal of Anaesthesiology. 2012;20(2):88-91.

8. Kloub R, Al-Qudah N. Analysis of patients' anesthesia experience at the Royal Jordanian rehabilitation center: a survey of anesthetic practice. JRMS. 2004;11(1):59-62.

9. Hepner LD, Bader MA, Hurwitz S, Gustafson M, Tsen CL. Patient satisfaction with preoperative assessment in a preoperative assessment testing clinic. Anesth Analg. 2004;98:1099-1105.

10. Lee A, Lum ME. Measuring anaesthetic outcomes. Anaesth Intensive Care. 1996;24(6):685-693. 


\section{Publish your work in this journal}

Patient Related Outcome Measures is an international, peer-reviewed, open access journal focusing on treatment outcomes specifically relevant to patients. All aspects of patient care are addressed within the journal and practitioners from all disciplines are invited to submit their work as well as healthcare researchers and patient support groups.
The manuscript management system is completely online and includes a very quick and fair peer-review system. Visit http://www.dovepress. com/testimonials.php to read real quotes from published authors.

Submit your manuscript here: http://www.dovepress.com/patient-related-outcome-measures-journal 